\title{
Effectiveness of Constructivism Based Learning Models Against Students Mathematical Creative Thinking Abilities in Indonesia; A Meta-Analysis Study
}

\author{
Maximus Tamur ${ }^{1,2}$, Dadang Juandi ${ }^{1}$ \\ \{maximustamur@upi.edu ${ }^{1}$ \} \\ Departemen Pendidikan Matematika, Universitas Pendidikan Indonesia, Jl. DR. Setiabudi No 229, \\ Bandung, 40154 Indonesia $^{1}$, \\ Program Studi Pendidikan Matematika, Universitas Katolik Indonesia Santu Paulus Ruteng, J1. Jend. \\ A. Yani.No. 10 Ruteng, 86518 Indonesia $^{2}$
}

\begin{abstract}
The purpose of this meta-analysis review is to examine the effectiveness of the application of constructivism-based learning models to the mathematical creative thinking abilities of secondary school students in Indonesia. This meta-analysis analyzes 33 effect sizes from 33 primary studies that met the inclusion criteria and published them in ERIC documents, journal articles, and proceedings from 2010 to 2019. Data were analyzed using CMA (Compherensive Meta-Analysis) software designed to determine publication bias and effect size. As a result of the analysis, the combined effect size was 0.884 based on the random-effects model. These results can be interpreted that the average student who was ranked 13th in the experimental class, the same as students who were ranked 6th in the control class. The results of the analysis of the mediator variables found that all variables are related to the effect size. The strongest relationship was found for the research class variables and sample size. There is evidence that constructivism-based learning models are more effective if applied in conditions of a sample size of 1-30 students. These facts are considered by mathematics education practitioners in applying constructivism-based learning models in the future.
\end{abstract}

Keywords: Creative Thinking Ability, Constructivist-Based Learning Models, Metaanalysis, Mathematics Education

\section{Introduction}

Since the last decade in Indonesia, it has been seen that many experimental studies have been conducted to reveal the effect of the application of constructivism-based learning models on students' mathematical creative thinking abilities. However, until now in the literature, there is no research that combines the findings obtained in the study. Literature reviews from the same studies, sometimes showing conflicting results [1]. On the other hand, the research review must provide comprehensive and in-depth conclusions [2], [3], [4].

Highlighting this gap is a meta-analysis study needed with the aim of integrating and interpreting the findings of primary studies [5], [6]. The meta-analysis provides in-depth and convincing conclusions [2], [4] so it is useful for policy making [7]. Thus, the findings of this study provide an impact for practitioners to decide under what conditions the application of 
constructivism-based learning models is effective in improving students' mathematical creative thinking abilities.

Previously, Kadir had done similar work in 2017 aimed at evaluating the effects of learning interventions on students' mathematical thinking skills [8]. In addition, in Indonesia a metaanalysis study has been carried out on the effectiveness of the problem-based learning model on the mathematical problem solving abilities of secondary school students [9]. There are no specific studies on the effectiveness of constructivism-based learning models on mathematical abilities, especially students' mathematical creative thinking. As a result, a picture of how the effects of constructivism-based learning are viewed from various variables, such as sample size, years of research carried out, school levels and others have not been evaluated.

These reasons indicate that a detailed meta-analysis of the efficacy of constructivism-based learning models on mathematical creative thinking skills from 2010 to 2019 is needed to test teaching models and to see the overall pattern clearly. This encourages researchers to evaluate the application of constructivism-based learning to students' mathematical creative thinking abilities. In this case, the following questions are examined:

1. Does the application of constructivism-based learning models produce greater effect sizes on students' mathematical creative thinking abilities than conventional learning?

2. Are there significant differences between the sizes of the effects of constructivism-based learning studies according to the year of study?

3. Are there significant differences between the effect sizes of constructivism-based learning according to school level?

4. Are there significant differences between the size of the effects of constructivism-based learning according to sample size?

5. Are there significant differences between the effect sizes of constructivism-based learning according to grade level?

\section{Method}

The general stages of meta-analysis research are; first, inclusion criteria were determined for the studies analyzed. Second, the procedure for collecting empirical data and coding of study variables will be explained. Third, statistical techniques to investigate the relationship between study variables and effect sizes [6], [10]. This research follows these stages.

\subsection{Inclusion Criteria}

The inclusion criteria in this study are the eligibility standards used in selecting primary studies namely; (a) the results of experimental and quasi-experimental research in Indonesia about constructivist-based learning; (b) in the form of Journal articles, proceedings, master's theses and doctoral dissertations; (c) publication in at least the last decade (2010-2019); and (d) has sufficient statistical information for the transformation of effect sizes namely; average, standard deviation and sample size.

\subsection{Locating the Studies}

Empirical data were obtained from electronic databases such as ERIC (https:/eric.ed.gov/?journals) and SAGE Publishing (https:/us.sagepub.com/en- 
us/name/journals). Furthermore, to reach Indonesian language search articles use the GOOGLE SCHOLAR and PORTAL GARUDA search engines. In this research, studies collected using the search engine from various reputable international journals, namely the International Electronic Journal of Mathematics Education (IEJME), International Journal of Instruction (IJI), Journal of Education and Practice (JEP), Journal of Mathematics Education ( JME) and Journal of Technology and Science Education (JOTSE). In addition, national journals were also obtained, namely the Mathematics Education Research Journal (JPM), the Mathematical Didactic Journal (JDM), Indonesian Mathematics Sociaty (Indoms J.M.E). This stage produced 48 primary studies and based on inclusion criteria, 33 major studies met the eligibility for analysis.

\subsection{Test of Reliability}

The data collection tool in this meta-analysis is the encoding sheet. This form of coding was developed to improve reliability in the suitability of the studies involved. Two coders extract data from the primary study into separate coding sheets, then compare them. If there is still data that is not the same then verify it again. This stage is done so that the data analyzed is not wrong. In general, meta-analysis research suffers from publication bias caused by subjective publications. To avoid subjective publication, it is necessary to calculate how many studies that will make the measure of zero influence have to be included in the analysis [11]. For the purpose of determining whether there are subjective publications or not, funnel charts can be taken into account. Figure 1 displays the research funnel plot.

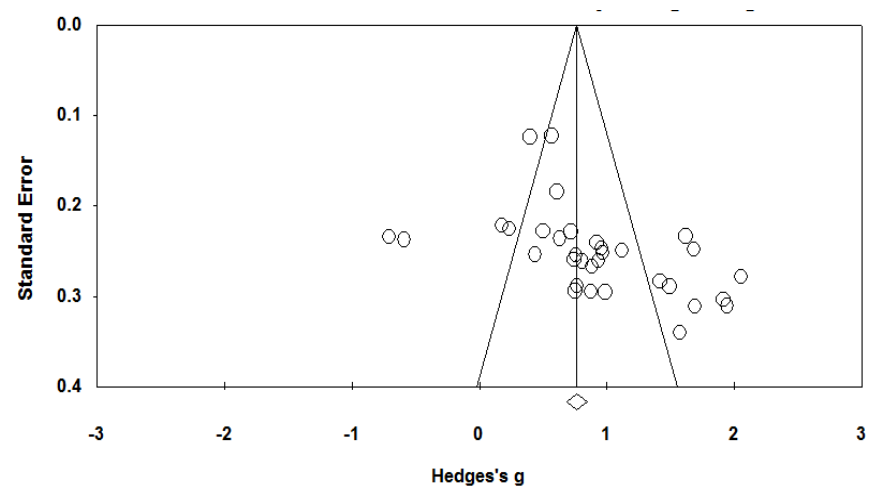

Fig. 1. Research Funnel Plots.

Based on the funnel chart, it is necessary to look at other values regarding subjective publication because some of the studies included in this study are outside the graph. One of the values used to express subjective publications is the value of Rosenthal safe $\mathrm{N}$. The calculation results, obtained by Rosenthal safe $\mathrm{N}$ value that is equal to 3382 . This value was found to be greater than the observed value of 33 so according to the Rosenthal method, there were no subjective publications in this study. Furthermore, according to the Orwin method, the value of Hedge's in the observed study was 0.76445 , greater than the significance level of 0.05 . Referring to the statement [12] that the results of the meta-analysis are resistant to publication bias. 


\subsection{Statistical analysis}

The application that helps with data analysis is the Comprehensive Meta-Analysis (CMA) program. The Hedge's g equation is used to determine the effect size index and based on the classification [13] as shown in the following Table 1:

Table 1. Interpretation of Effect Size

\begin{tabular}{cc}
\hline Range of Effect Size & Interpretation of Effect Size \\
\hline$-0.15 \leq \mathrm{ES}<0.15$ & no effect \\
$0,15 \leq \mathrm{ES}<0,40$ & low effect \\
$0,40 \leq \mathrm{ES}<0,75$ & medium effect \\
$0.75 \leq \mathrm{ES}<1.10$ & high effect \\
$1,10 \leq \mathrm{ES}<1,45$ & very high effect \\
$\mathrm{ES} \geq 1,45$ & excellent effect \\
\hline
\end{tabular}

The CMA program will measure the $\mathrm{Z}$ value used to check the significance and evaluate the heterogeneity between classes of variables, namely the Qb (Qbetween) value. If Zhitung > Ztable with $\mathrm{p}<0.05$, the null hypothesis is rejected [5]. This shows that the application of constructivism-based learning styles will have an effect on students' mathematical creative thinking abilities compared to conventional approaches. The random-effects model is used when the effect size is statistically heterogeneous $(\mathrm{Qb}>\chi 2.95 ; \mathrm{p}<0.05)$ meaning the null hypothesis that the effect size between studies is homogeneous is not accepted [14]. This means that effect sizes between studies or study groups may not measure the same population parameters [5]. In other words, there is a statistically significant difference in the average effect size for each variable class.

\section{Result and Discussion}

Based on calculations using CMA software as a whole, the effect sizes and confidence interval limits of each study is shown in the following Table 2:

Table 2. Combined effect sizes and condidence intervals.

\begin{tabular}{lccc}
\hline \multirow{2}{*}{ Author } & Effect & \multicolumn{2}{c}{ Confidence Interval } \\
\cline { 3 - 4 } & Size & Lower limit & Upper limit \\
\hline Hasratuddin, 2010 & 0.4 & 0.16 & 0.64 \\
Noer, 2011 & 0.61 & 0.25 & 0.97 \\
Ismaimuza, 2013 & 0.76 & 0.26 & 1.26 \\
Sumarmo, dkk, 2012 & $\mathbf{- 0 . 7 1}$ & -1.17 & -0.25 \\
Sugilar, 2013 & 0.96 & 0.47 & 1.44 \\
Suhandri, 2013 & 0.92 & 0.45 & 1.39 \\
Happy \& Widjajanti, 2014 & 1.69 & 1.08 & 2.3 \\
Darusman, 2014 & 0.5 & 0.05 & 0.95 \\
Nur \& Abdullah, 2014 & 1.57 & 0.91 & 2.24 \\
Mawaddah, Kartono, \& Suyitno, 2015 & 0.93 & 0.42 & 1.44
\end{tabular}




\begin{tabular}{lccc} 
Atikasari \& Kurniasih, 2015 & 0.97 & 0.47 & 1.46 \\
Lince 2016 & 1.91 & 1.32 & 2.51 \\
Syafti, 2016 & 1.49 & 0.93 & 2.06 \\
Fitriyantoro \& Prasetyo, 2016 & 0.72 & 0.27 & 1.17 \\
Apriliani \& Suyitno, 2016 & 0.87 & 0.3 & 1.45 \\
Marliani, 2016 & 0.99 & 0.41 & 1.57 \\
Fadillah, 2016 & 0.74 & 0.24 & 1.25 \\
Samo, Darhim, \& Kartasasmita, 2017 & 2.05 & 1.51 & $\mathbf{2 . 6}$ \\
Saironi \& Sukestiyarno, 2017 & 0.81 & 0.3 & 1.32 \\
Aripin \& Purwasih, 2017 & 0.23 & -0.21 & 0.68 \\
Yenni \& Putri, 2017 & 0.18 & -0.26 & 0.61 \\
Yudiawati \& G. P, 2017 & 0.44 & -0.06 & 0.93 \\
Septian \& Rizkiandi, 2017 & -0.59 & -1.05 & -0.12 \\
Heryandi, 2018 & 0.76 & 0.2 & 1.33 \\
\hline & Effect & Confidence Interval \\
\cline { 2 - 4 } & Size & Lower limit & Upper limit \\
\hline Rahayu, Akbar, \& Afrilianto, 2018 & 1.68 & 1.2 & 2.17 \\
Cahyati, Muin, \& Musyrifah, 2018 & 0.88 & 0.36 & 1.41 \\
Wijayanti, Maulida, Hutajulu, \& Hendriana, 2018 & 1.94 & 1.34 & 2.55 \\
Usman \& Halim, 2018 & 1.12 & 0.63 & 1.61 \\
Warmi, 2017 & 1.62 & 1.16 & 2.08 \\
Budiman \& Syayyidah, 2018 & 0.63 & 0.17 & 1.09 \\
Risnawati, Amir, Lubis, \& Syafri, 2018 & 1.42 & 0.86 & 1.97 \\
Tambunan, 2019 & 0.57 & 0.33 & 0.81 \\
Elfira, Sudia, \& Masi, 2019 & 0.75 & 0.18 & 1.33 \\
\hline & & & \\
\hline
\end{tabular}

Based on Table 2, effect sizes were found to be positive in most studies. Table 3 displays the results of the meta-analysis based on the estimation model.

Table 3. Comparison of meta-analysis result acconrding to the effect model.

\begin{tabular}{|c|c|c|c|c|c|c|c|c|}
\hline \multirow{2}{*}{$\begin{array}{l}\text { Estimation } \\
\text { model }\end{array}$} & \multirow[b]{2}{*}{$\mathrm{n}$} & \multirow[b]{2}{*}{$\mathrm{Z}$} & \multirow[b]{2}{*}{$\mathrm{P}$} & \multirow[b]{2}{*}{ Q } & \multirow{2}{*}{$\begin{array}{c}\text { I-squared } \\
(p=0.05)\end{array}$} & \multirow{2}{*}{$\begin{array}{l}\text { Effect } \\
\text { Size }\end{array}$} & \multicolumn{2}{|c|}{ Confidence Interval } \\
\hline & & & & & & & $\begin{array}{c}\text { Lower } \\
\text { limit }\end{array}$ & $\begin{array}{l}\text { Upper } \\
\text { Limit }\end{array}$ \\
\hline $\begin{array}{l}\text { Fixed effects } \\
\text { model }\end{array}$ & 33 & 18.841 & 0.000 & 208.425 & 84.647 & 0.764 & 0.685 & 0.884 \\
\hline $\begin{array}{l}\text { Random } \\
\text { effects model }\end{array}$ & 33 & 8.36 & 0.000 & 208.425 & 84.647 & 0.884 & 0.677 & 1.091 \\
\hline
\end{tabular}

Based on Table 3, when the estimated model chosen is the fixed effect model, the combined effect size is 0.764 with the category of high effect [13] at a $95 \%$ confidence interval, lower limit 0.685 and upper limit 0.884 . As a result of the statistical significance test, a $\mathrm{z}$ value of 17,841 was obtained. This result was statistically significant with $p<0.001$. Based on Table 3 shows that the $\mathrm{Qb}$ value is 208.425 greater than 84,647 with 32 degrees of freedom in table $\chi 2$. Thus, the effect size distribution was found to be heterogeneous at $p<0.05$. Therefore the estimated estimation model is the random-effects model.

Based on the random-effects model in Table 3, the combined effect size was found to be 0.884 as a high effect [13] with a $95 \%$ confidence interval, a lower limit of 0.677 and an upper 
limit of 1.091. Statistical significance test results, obtained $z$ values of 7,878 . This result was said to be statistically significant at $\mathrm{p}<0.001$. This means that the application of constructivismbased learning models produce greater effect sizes on students' mathematical creative thinking abilities than conventional learning.

Furthermore, the effect sizes of 33 studies were examined based on research variables, namely variables based on the year of publication, variables based on school level, variables based on the sample size, and variables based on class. Table 4 below is a summary of the results of the calculation of effect sizes which are calculated using the CMA program.

Table 4. Summary of ES calculation results based on variables.

\begin{tabular}{|c|c|c|c|c|}
\hline Variable & $\mathrm{n}$ & Group & Hedge's g & $\mathrm{Qb}_{\mathrm{b}}$ \\
\hline \multirow[b]{2}{*}{ Research Year } & 11 & $2010-2015$ & 0.64 & \multirow[b]{2}{*}{$0.901 * * *$} \\
\hline & 22 & 2016-2019 & 0.72 & \\
\hline \multirow{3}{*}{$\begin{array}{l}\text { School level research is } \\
\text { carried out }\end{array}$} & 19 & Junior high school & 0.793 & \multirow{3}{*}{$2.686^{* * *}$} \\
\hline & 11 & Senior High School & 0.657 & \\
\hline & 2 & Vocational high School & 1.091 & \\
\hline \multirow{2}{*}{ Experimental Sample Size } & 14 & 31 or less & 0.959 & \multirow{2}{*}{$19.283 * * *$} \\
\hline & 19 & 32 or over & 0.54 & \\
\hline \multirow{6}{*}{ Class } & 6 & VII & 0.95 & \multirow{6}{*}{$19.868 * * *$} \\
\hline & 11 & VIII & 0.67 & \\
\hline & 2 & IX & 1.13 & \\
\hline & 8 & $\mathrm{X}$ & 0.7 & \\
\hline & 5 & $\mathrm{XI}$ & 0.74 & \\
\hline & 1 & XII & 1.12 & \\
\hline
\end{tabular}

According to the random model the effect size of 33 studies determined by 0.884 shows that learning that applies constructivism-based learning models results in a greater effect size on students' mathematical creative thinking abilities than conventional approaches. This means that the application of constructivism-based learning models are inquiry models (Inquiry-Based Learning), discovery learning models (Discovery Learning), project-based learning models, and problem-based learning models and cooperative learning (cooperative learning) have a greater positive effect than conventional approaches. These results represent that the average student whose constructivism-based learning model exceeds the ability of $79 \%$ of students in conventional classes who are initially the same. This result can also be seen by applying the constructivist-based learning model of students moving from the 50th percentile to the 79th percentile in mathematical critical thinking skills. In addition, ES is 0.884 if it is confirmed by the interpretation table developed by Coe in 2002 [15], It can be assumed that students who are ranked 13th in the experimental class, are the same as students who are ranked 6th in the control class.

This result is consistent with previous studies in Turkey. The researchers found an effect size of 0.959 when they synthesized 32 studies comparing the effectiveness of cooperative learning models and conventional learning on student academic achievement. [12]. Similar results were reported in a study in Indonesia that reported an effect size of 0.94 for the effectiveness of problem based learning models [9]. In the same study an effect size of 0.24 was found in high school student subjects. This study shows quite similar results, a fact that shows an overall trend. 
Subsequently, subgroup analyzes were performed to investigate the relationship between variables and study effect sizes. When Table 4 is examined, it appears that the study group conducted in 2010 to 2015 has a combined effect size of 0.64 (moderate effect) and the study group between 2016 and 2019 has a combined effect size of 0.72 (moderate effect). Homogeneity test results show that the Qb value is 0.901 smaller than the value of 3.841 with a significance level of 0.05 and the degree of freedom (dfQ) is 1 . This means that there is no significant difference between study groups based on the study year. So the year of research is related to the size of the study effect but it is not strong.

Furthermore, based on the level of education, the analysis shows that the effect size of the study group conducted in junior high school (SMP) 0.793 (high effect) is greater than the effect size of the study group conducted in senior high school (SMA) by 0.657 (middle effect). However, both are smaller than the effect size in a study conducted in vocational high schools which is 1,092 (high effect). Homogeneity test results obtained Qb value of 2,686 smaller than the value of 5.99 at a significance level of 0.05 and the degree of freedom is 2 . That is, there is no significant difference in the effect size between levels of education. This result is not supported by previous research findings that the application of problem-based learning models is more effective in junior high schools than in senior high schools [9]. However, there is a tendency that the application of constructive-based learning models is more effective in junior high schools. But it can't be explained why this happened.

Based on Table 4 it was found that the sample size variable is related to the effect size. The sample size arranged in the range of 1-31 students has a combined effect size of 1.11 (very high effect). Whereas the sample size arranged in the range of 32 or more students has a combined effect size of 0.63 (moderate effect). Homegeneity test results show the $\mathrm{Qb}$ value of 19,283 is greater than the value of 3,841 at a significance level of 0.05 and the degree of freedom equal to 1 . These results indicate that the application of constructive-based learning models is more effective under conditions of sample sizes of 1-31 students.

Finally, based on the research class it was found that the size of the combined effects in the study groups conducted in grades VII, VIII, IX, X, XI, and XII were 0.95 (high effect), 0.67 (moderate effect), 1.13 (very high effect); 0.70 (medium effect), 0.74 (medium effect), and 1.12 (very high effect). As a result of homogeneity test, the Qb value of 19,869 is greater than the value of 11.07 at a significance level of 0.05 and the degree of freedom equal to 5 . This indicates that the class of research is related to the size of the study effect. There is evidence that constructivism-based learning models are effective when applied in grades IX and XII.

\section{Conclusion}

This research has been conducted to investigate the effectiveness of applying constructivism-based learning models. Based on the random-effects model the combined effect size in this study was 0.884 (95\% confidence interval, lower limit 0.677 , and upper limit 1.091). The size of the effect is accepted as a high effect. This strong effect size indicates that using constructivism-based learning models in mathematical classrooms may be quite effective.

Judging from the research variables based on the year of publication, there were no significant differences between groups. But the size of the two effects can be said to have similar trends and tend to increase. Judging from the variables according to school level, it can be said that there are significant differences in effect sizes between groups. In other words, the application of problem-based learning models as part of constructivism-based learning models 
is more effective in junior high schools and vocational schools than in high schools. The analysis of mediator variables or study characteristics found that all four variables were related to effect size. But the strongest relationship is the sample size variable and the research class. The research findings show that the effect size in the sample range of 1-31 students is greater than the effect size in the range of 32 students or more. The size of the effects of studies conducted in class IX is greater than classes VII and VIII. Likewise, the size of the effects of studies conducted in class XII is greater than classes X and XI. These facts are considered by education practitioners in applying constructivism-based learning models in the future.

Acknowledgments. The author thanks the Paulus Ruteng Foundation, which funded this research. Thanks to Prof. James J Lindsay through ResearchGate for providing a very important reference aid for this research.

\section{References}

[1] Bayraktar, S.: A meta-analysis of the effectiveness of computer-assisted instruction in science education. J. Res. Technol. Educ. 34, pp. 173-188, (2001)

[2] Kulik, J. A., Bangert, R. L. \& Williams, G. W.: Effects of computer-based teaching on secondary school students. J. Educ. Psychol. 75, pp.19-26, (1983)

[3] Randolph, J. J.: A Guide to Writing the Dissertation Literature Review in Software Engineering. Pract. Assessment, Res. Eval. 14, pp. 1-13, (2009)

[4] Siddaway, A. P., Wood, A. M. \& Hedges, L. V.: How to Do a Systematic Review: A Best Practice Guide for Conducting and Reporting Narrative Reviews, Meta-Analyses, and Meta-Syntheses. Annu. Rev. Psychol. 70, pp. 747-770, (2019)

[5] Borenstein, M. \& Hedges, L. V.: Introduction to Meta-Analysis. WILEY A John Wiley and Sons, Ltd, Publication, (2009)

[6] Glass, G. V.: Primary, Secondary, and Meta-Analysis of Research Educ. Res. 5, 10 p. 3-8, (1976)

[7] Freeman-Green, S. M, O'Brien C Wood C L \& Hitt S B.: Effects of the SOLVE strategy on the mathematical problem solving skills of secondary students with learning disabilities Learn. Disabil. Res. Pract. 30, 2 p. 76-90, (2015)

[8] Kadir, K.: Meta-Analysis of the Effect of Learning Intervention Toward Mathematical Thinking on Research and Publication of Student. TARBIYA J. Educ. Muslim Soc. 4, pp. 162-175, (2017)

[9] Asror, A. H.: Meta-Analisis: Problem Based Learning. Unnes pp. 508-513, (2016)

[10] Hunter, J. E. \& Schmidt, F. L.: Methods of meta analysis: Correcting error and bias in research finding. SAGE Publications (2004)

[11] Rosenthal, R.: The 'File Drawer Problem' and Tolerance for Null Results. Jnl. Jsme 64, pp. 638641, (1979)

[12] Bayir, O. G. \& Bozkurt, M.: Effectiveness of Cooperative Learning Approaches Used in the Course of Social Studies in Turkey: A Meta-Analysis Study. Online Submiss. 4, pp. 171-192, (2018)

[13] Thalheimer, W. \& Cook, S.: Effect_Sizes_pdf5.pdf. Work Learn. Recearch pp. 1-9, (2002)

[14] Demir, S. \& Başol, G.: Effectiveness of computer-assisted mathematics education (CAME) over academic achievement: A meta-analysis study. Kuram ve Uygulamada Egit. Bilim. 14, pp. 2026-2035 (2014)

[15] Coe R.: It' s the Effect Size, Stupid Educ. Res. September p. 1-18, (2002) 